International

Medical Society

http://imedicalsociety.org

\title{
Analysis on the Doula's Influence in Childbirth Care at a Maternity
}

Ricardo de Sousa Soares ${ }^{1}$, Aysla de Albuquerque Santana ${ }^{2}$, Ulisses Umbelino dos Anjos ${ }^{3}$, Rodrigo Pinheiro Toledo Vianna ${ }^{4}$, Luciano Bezerra Gomes ${ }^{5}$, Waglania de Mendonça Faustino e Freitas ${ }^{6}$, Juliana Sousa Soares de Araújo7, Juliana Sampaio8, Dandara Barbosa Palhano ${ }^{9}$, Adernanda De Rocco Guimarães ${ }^{10}$, Alexandre José de Melo Neto ${ }^{11}$, Luiza Soares Guerra ${ }^{12}$

\section{Abstract}

Background: Childbirth and labor, in the past decades, have been suffering modifications towards the increasing necessity of humanization at labor and childbirth practices. The doulas have been presenting a important role in women's support with good results in some countries. This article intends to analyze the implementation of a voluntary doula's program at a large maternity in Brazil's public health system.

Methods: A quantitative, cross-sectional study was realized between June, 2015, and March, 2016. The presence or absence of the doula's support was considered along side the labor type, pain medications use, oxytocin use and skin-to-skin contact between mother and child. It was also analyzed women's satisfaction and the correlation with the doula's support. Pearson's chi-squared test and a 0.05 statistical significance was used.

Findings: A statistic association between the doula's support and a decrease in cesarean sections number was found. Considering women with vaginal deliveries, a statistic association between the presence of the doulas and a increase in skin-to-skin contact and women satisfaction was reported. No significant correlation between the doulas and the use of pain medications, oxytocin use and episiotomy was found.

Conclusions: The results tend to related the presence of the doulas with some good practices indicators, matching researches in other countries. Regardless of the cross-sectional study limitations, the presence of the voluntary doula's program is perceived as satisfactory.
1 Student in Health Decision Models, Federal University of Paraíba. Professor at Department of Health Promotion, Federal University of Paraíba, *

2 Medical student. Federal University of Paraíba, *

3 PhD in Statistics. Department of Statistics, Federal University of Paraíba, ${ }^{*}$

$4 \mathrm{PhD}$ in Public Heath. Department of Nutrition, Federal University of Paraíba, ${ }^{*}$

$5 \mathrm{PhD}$ in Clinical Medicine. Department of Health Promotion, Federal University of Paraíba, *

6 PhD in Public Heath. Department of Nursing, Federal University of Paraíba,*.

7 Master in Health Decision Models. Department of Health Promotion, Federal University of Paraíba,

$8 \mathrm{PhD}$ in Public Health. Department of Health Promotion, Federal University of Paraíba, .

9 Master in Health Decision Models. Federal University of Paraiba.

10 Sanitarian,*.

11 Family's Doctor Specialist. Department of Health Promotion, Federal University of Paraíba, ${ }^{*}$.

12 Medical student. Federal University of Paraíba, ${ }^{*}$

*: João Pessoa, Paraíba. Brazil.

Contact information:

Ricardo de Sousa Soares.

”' ricardosousasoares@gmail.com

Keywords

Humanizing Delivery;

Parturition; Labor, Obstetric;

Doula. 


\section{Introduction}

Childbirth scenario in Brazil has been going trough intense modifications in the past few years, many produced by the expansion of movements for Labor and Childbirth Humanization. Those, in the last years, have been institutionalized, receiving legal, financial and technical support seeking the implementation of good maternity practices at materno and child care. Among those incentives, the right of a caregiver and reduction of unnecessary interventions at labor are found. Such changes seek the decrease of cesarian and infant-maternal mortality numbers. [1]

Childbirth scenario is gaining new perspectives at humanization context; women's autonomy increases as they assume the role of protagonist along side the health professionals team. The humanization purpose is offer more freedom and autonomy to the parturient in the decision of which type of labor, conditions and space she will prefer, as well as who will support her in the procedure and which birth positions she would like to assume, allowing freedom of movement, feeding and expression.

In order to support such protagonism, the immersion of the doulas is being valued. Doulas are professionals trained to provide physical and emotional support, offering different types of care, such as massages, aliments and support to desired positions. The doulas are not health professionals, neither should replace any member of the multidisciplinary team or the family companion, often as helpless and insecure as the parturient. [2]

Scientific evidences have been pointing the contributions of the doulas at the decrease in unnecessary biomedical intervention at the prepartum and postpartum and, in result, the decrease in the numbers of cesarian sections. [3, 4, 5] With such contribution, there is a increase in the insertion of the doulas at the childbirth scenario, in the vaginal birth centers as well as in the high-risk and basicrisk maternities.
This article analyses aspects related with the support of the doulas at a large maternity in Brazil's northeast, which has been going trough the implementation of a Voluntary doula's program. It is intended to analyze the satisfaction of women supported by the doulas, and if there is any statistic relation between the number of woman assisted by the doulas and the amount of vaginal birth and cesarians. It also intends to analyze the relation between the doula support in labor and the use of oxytocin and pain medicines, as well as the insurance of a skin-to-skin contact between the mother and the newborn at the first moment after birth and the general satisfaction of the parturient in the childbirth process.

\section{Methods}

This study was a quantitative, cross-sectional study, realized at a large maternity in the city of João Pessoa, state of Paraíba, in Brazil's northeast, between July (2015) and March (2016). The maternity was chosen for being part of the public health system, having a large request of basic-risk and high-risk childbirths and for owning a voluntary doula program since 2013. The doulas take weekly shifts at the service and offer support for women in labor at the obstetric center according the parturient's request for receiving, or not receiving, this sort of support. There is a small number of doulas and as they offer an individual care, the numbers are insufficient for them to offer support to all parturients at the local.

The survey instrument was the likert scale including 11 points for questions about general satisfaction in labour, and for women assisted by the doulas, the satisfaction with the support service. The database of interviewed women was linked with the maternity's information system to extract the variables. Concerning satisfaction, was considered as barely satisfied women with grades between 0 and 6, moderately satisfied women with answers 
between 7 and 8, and very satisfied women with answers between 9 and 10 .

This sample is comprised of 370 women, randomly chosen. The postnatal mothers were interviewed still at the maternity in the immediate puerperium. The inclusion criteria were women with low risk gestation and labor, above 18 years old. This research was approved by the Center of Health Science's ethics in research's committee, at the Federal University of Paraíba CAAE 42538515.4.000.5188.

The data was analyzed through IMB SPSS (v.22). Pearson's chi-squared test was complied to compare being supported by the doulas and the denouement for normal vaginal deliveries or cesarean deliveries. A logistic regression for multivariate analysis was realized for women with natural childbirths, doing a parallel between the variable women supported by the doulas with the variables childbirth satisfaction, skin-to-skin contact, oxytocin use, pain medications use, and episiotomy. A 0.05 statistical significance was regarded.

\section{Results}

Among the 370 interviewed women, 198 completed elementary/middle school, 158 studied until hight school and 14 reached higher education. $34.9 \%$ of women had an paid employment. The family income of the majority of the women was up to 2 minimum wages (80\%), and $20 \%$ won more than 2 minimum wages. The demographic database are presented at Table 1.

Considering the labor channel, 237 women (64.1\%) had normal vaginal births, and 133 women (35.9\%) had cesarean sections (Table 2). 127 women were supported by the doulas (34.3\%).
Table 1. Sociodemographic's statistics description $(\mathrm{N}=370)$.

\begin{tabular}{|c|c|c|}
\hline Characteristics & Categories & N (\%) \\
\hline \multirow{4}{*}{ Age (years) } & $<25$ years & $171(46.2)$ \\
\hline & 26-30 years & $95(25.7)$ \\
\hline & 30-35 years & $74(20)$ \\
\hline & $>35$ years & $30(8.1)$ \\
\hline \multirow{3}{*}{ Ethnicity } & White & $114(30.8)$ \\
\hline & African/Biracial & $246(66.4)$ \\
\hline & Other & $10(2.8)$ \\
\hline \multirow{4}{*}{ Education } & $\begin{array}{l}\text { Illiterate/ Elementary school } \\
\text { Incomplete }\end{array}$ & $100(27)$ \\
\hline & Elementary School graduate & $98(26.5)$ \\
\hline & Middle/High School graduate & $158(42.7)$ \\
\hline & higher education & $14(3.8)$ \\
\hline \multirow{2}{*}{ Employment } & Yes & $129(34.9)$ \\
\hline & No & $241(65.1)$ \\
\hline \multirow{5}{*}{ Religion } & Catholic & $154(41.6)$ \\
\hline & Afro-brazilian & $4(1.08)$ \\
\hline & Protestant & $119(32.2)$ \\
\hline & Not declared & $91(24.6)$ \\
\hline & Others & $2(0.54)$ \\
\hline \multirow{5}{*}{ Family income } & Less than 1 Minimum Wage & $74(20)$ \\
\hline & 1 to 2 Minimum Wages & $222(60)$ \\
\hline & 2 to 3 Minimum Wages & $51(13.8)$ \\
\hline & 3 to 4 Minimum Wages & $16(4.3)$ \\
\hline & 4 or more Minimum Wages & $7(1.9)$ \\
\hline \multirow{3}{*}{$\begin{array}{l}\text { Childbirth } \\
\text { satisfaction }\end{array}$} & Very satisfied & $266(71.9)$ \\
\hline & Moderately Satisfied & $67(18.1)$ \\
\hline & Unsatified & $37(10)$ \\
\hline \multirow{3}{*}{$\begin{array}{l}\text { Satisfaction with } \\
\text { the doulas }\end{array}$} & Very satisfied & $95(74.8)$ \\
\hline & Moderately Satisfied & $21(16.5)$ \\
\hline & Unsatisfied & $11(8.7)$ \\
\hline
\end{tabular}

Table 2. Support with doula compared with cesarian or vaginal delivery.

\begin{tabular}{|l|c|c|c|c|c|c|}
\hline \multicolumn{1}{|c|}{ Delivery } & $\begin{array}{c}\text { With Doula Support } \\
(\mathbf{N = 1 2 7})\end{array}$ & $\begin{array}{c}\text { Without Doula Support } \\
(\mathbf{N = 2 4 3 )}\end{array}$ & Odds ratio & $\mathbf{C l}(\mathbf{9 5 \% )}$ & $\mathbf{X}^{\mathbf{2}}$ & p-valor \\
\hline Cesarean Delivery & $28(22 \%)$ & $105(43.2 \%)$ & 0.510 & $(0.357-0.729)$ & 16.224 & 0.000 \\
\hline Vaginal Delivery & $99(78 \%)$ & $138(66.8)$ & 1.373 & $(1.189-1.584)$ & & \\
\hline
\end{tabular}


Table 3. Support of doulas in Vaginal Delivery Compared with Interventions and Women's Satisfaction $(\mathrm{N}=237)$

\begin{tabular}{|l|c|c|c|c|c|c|}
\hline \multicolumn{1}{|c|}{ Variable } & $\begin{array}{c}\text { With Doula Support } \\
(\mathbf{N = 9 9 )}\end{array}$ & $\begin{array}{c}\text { Without Doula Support } \\
(\mathbf{N = 1 3 8 )}\end{array}$ & Odds ratio & Cl (95\%) & $\mathbf{X}^{2}$ & p-valor \\
\hline $\begin{array}{l}\text { Skin-to-skin } \\
\text { contact }\end{array}$ & $76(76.8 \%)$ & $75(54.3 \%)$ & 1.414 & $(1.171-1.704)$ & 12.533 & 0.000 \\
\hline $\begin{array}{l}\text { Childbirth } \\
\text { satisfaction }\end{array}$ & $94(94.9 \%)$ & $120(87 \%)$ & 1.092 & $(1.009-1.182)$ & 4.203 & 0.040 \\
\hline Episiotomy & $13(13.1 \%)$ & $9(6.5 \%)$ & 2.013 & $(0.896-4.525)$ & 2.991 & 0.084 \\
\hline Pain medication & $39(39.4 \%)$ & $46(33.3 \%)$ & 1.182 & $(0.841-1.660)$ & 0.921 & 0.337 \\
\hline Oxytocin & $23(23.2 \%)$ & $21(15.2 \%)$ & 1.527 & $(0.897-2.600)$ & 2.449 & 0.118 \\
\hline
\end{tabular}

Women's general satisfaction on the doulas was of $99.2 \%$, only $1(0.8 \%)$ declared herself as unsatisfied, although 95.3\% were very satisfied.

Childbirth satisfaction rates were of $90 \%$, among these, $71.9 \%$ were very satisfied,18.1\% were moderately satisfied and $10 \%$ unsatisfied. This rate is of $91.3 \%$ in women with the doula's support, and of $89.3 \%$ among women not supported by the doulas. Skin-to-skin contact was present in 58.6\% percent of women (98.4\% among those supported by the doulas), episiotomy rates were about $7.8 \%$ and oxytocin use were about $22.2 \%$ (Table 3). The support of the doula represented a significant statistic relation with decrease of cesareans ( $p$-value $<0.05$ ), presented at Table $2.78 \%$ of the women supported by the doulas had normal vaginal labors (22\% had cesarians), when in the non-supported by the doula's group the relation was of $56.8 \%$ vaginal childbirths to $43.2 \%$ cesarean sections (Table 2 ).

Considering women with normal vaginal childbirths, Pearson's chi-squared test pointed a significant positive association between women's birth satisfaction, with a Odds ratio of 1.092 Confidence Interval (Cl) 1.009 til 1.182 (p-valor 0.040), and the variable skin-to-skin contact 1.414 ( $p$-value 0.000) with $\mathrm{Cl}$ of 1.171 til 1.704. The episiotomy and pain medications variables did not present significant statistic relation with the doula's support [1] (Table 3).

\section{Discussion}

The doulas support presented a significant association with delivery by vaginal birth. Concerning women who realized vaginal delivery there was a statistic relation between the doula's presence and an increase on the frequency of skin-to-skin contact and of the general satisfaction towards the labor. It is important to highlight that in the maternity studied in this article, there is an Voluntary doula's Program, and there is as well obstetrical nurses acting in the prepartum and postpartum, although the support is still centered on the obstetrician with a hegemonic influence of the traditional obstetric model. However, the maternity has been investing in the good practices as well as in labor and birth humanization in the past few years.

The doula's support to women is associated with a decrease in the cesarean chances in about 0.5104 (0.357-0.729), being the absence of the doulas related with almost twice the numbers of cesarean deliveries. This result demonstrate that the presence of the doulas in the childbirth process can be an excellent support strategy in reduction of cesarean sections rates in the country, attending the purpose of reduction of cesareans numbers - still very high in Brazil - present in the infant and maternal Brazilian program. 1 Most likely, the emotional and physical support provided for women by the doulas in the childbirth event contribute to a satisfactory environment to vaginal delivery. Reports existent corrobo- 
rate the ideia that the doulas, by providing women physical and emotional comfort and orientations concerning the childbirth, increase tranquility and decrease anxiety levels. [6] The doulas support have been associated with reduction in cesarean and unnecessary intervention numbers [3, 4], and it is also related with increase of women satisfaction and decrease in financial costs. [4]

A larger frequency of skin-to-skin contact and a better perception about the women's satisfaction towards labor, were factors significantly related with the presence of the doula at normal vaginal childbirth. The doula's support, however, did not changed the scenario of episiotomy, oxytocin use and pain medicine use. The doula's support was associated with a 1.414 (1.171-1.704) improved chance of the women have skin-to-skin contact with the newborn, and a 1.092 (1.009-1.182) chance of being satisfied with the childbirth care. Is possible to considere, therefore, that the doula's presence in labor presents an important impact in safety sentiment for women, which strengthens her for the conduction of a normal vaginal childbirth.

A study realized comparing different maternities in Brazil presented a significant association between obstetrics assistance with a collaborative model, integrating medicine doctor, obstetrical nurses and doula, with decrease of oxytocin, decrease of artificial membrane rupture, increase of non-pharmacological methods, and decrease of episiotomy. [7] The doula's support is singly and strongly associated with the use of non-pharmacological pain control methods. [8] An association between being supported by the doulas in childbirth was related, positively, with breastfeeding in United Sates. [5]

It is believed that in this maternity analysis no significant relation was found with episiotomy, oxytocin use and pain medicine use as the traditional birth model is hegemonic at the maternity, and there is no integration with a team of obstetrician and obstetrical nurses in a collaborative model. The doula's performance and interdisciplinar relation have, in consequence, variations accordingly the on call team.

Rates considering the satisfaction towards the doulas, where $95.3 \%$ of women scored 9 or 10 , at a 0 till 10 scale, the total satisfaction was of $99.2 \%$ with only one woman pointing an unsatisfactory experience with the doula - presents that the doula's support was very well evaluated by women.

In relation towards childbirth, a study considering the labor satisfaction in Brazil's northeast found as results that $74 \%$ were very satisfied, $24 \%$ moderately satisfied and only $1.3 \%$ little satisfied. [9] A different study found that $70 \%$ evaluated the labor process as good or very good. [10] The $90 \%$ general satisfaction found in this article can be considered high, although the different methodology used diminishes the possibility of a comparison. The satisfaction towards the doula's was considered very high.

\section{Conclusions}

The doula's support was connected with a lower index of cesareans, improvement of skin-to-skin contact and childbirth satisfaction. It is important, although, highlight that this was a cross-sectional study, as being subjected to those studies limitations we can not predict if the association with doulas can really improve protection or if women naturally inclined to normal labors seek more the support of the doulas.

Considering the study limitations, those datas, for themselves, demonstrate that the Voluntary doula's Program at the maternity presented satisfactory results and therefore, should be amplified and stimulated. Its presence can be improved by actions related with changes in the interventionist practices centered in the biomedical care.

The manager group can empower those discussions and promote actions related with the multi professionals team and about protocols practiced in the maternity's routine. The effective humanization 
of childbirth, with an improvement in natural births numbers, in other words, without unnecessary biomedical interventions (that only turns vulnerable the parturient ant the newborn, damaging the conduction of a natural birth) goes beyond the presence of the doulas, being necessary changes in the environment and in institutional standards as well as in the health professionals practices. In every way, the presence of the doulas points to evolution of the care model towards the humanization of childbirth, which can be powered with a collaborative care model, strengthening the obstetrical nurses and improving the interaction between the doulas and the maternity's multidisciplinary team.

\section{Competing and Conflicting Interests}

All the authors have no conflict of interest.

\section{References}

1. Ministério da Saúde. Portaria GM/MS n 1.459, de 24 de Junho de 2011. Institui, no âmbito do SUS a Rede Cegonha. 2011.

2. Brüggemann OM. Evidence on support during labor and delivery: a literature review. In: Parpinelli MA, ed. Caderno de Saúde pública, Rio de Janeiro; 2005.

3. Paterno MT, Van Zandt SE, Murphy J, Jordan ET. Evaluation of a Student-Nurse Doula Program: An Analysis of Doula Interventions and Their Impact on Labor Analgesia and Cesarean Birth. Journal of Midwifery \& Women's Health. 2012;57(1):2834.

4. Chapple W, Gilliland A, Li D, Shier E, Wright E. An economic model of the benefits of professional doula labor support in Wisconsin births. WMJ. 2013;112(2):58-64.

5. Kozhimannil KB, Attanasio LB, Hardeman RR, O'Brien M. Doula Care Supports Near-Universal Breastfeeding Initiation among Diverse, Low-Income Women. Journal of Midwifery \& Women's Health. 2013;58(4):378-382.

6. Santos DS, Nunes IM. Doulas in delivery assistance: perceptions of nursing professionals. Escola Anna Nery. 2009;13:582-588.
7. Vogt $S E$, Silva KS, Dias MAB. Comparison of childbirth care models in public hospitals, Brazi. Revista de Saúde Pública. 2014;48:304-313.

8. Kozhimannil KB, Johnson PJ, Attanasio LB, Gjerdingen DK, McGovern PM. Use of nonmedical methods of labor induction and pain management among US women. Birth. 2013;40(4):227236.

9. Queiroz MVO, Jorge MSB, Marques JF, Cavalcante AM, Moreira KdAP. Quality of care indicators for delivery based upon mothers' satisfaction. Texto \& Contexto - Enfermagem. 2007;16:479-487.

10. Domingues RMSM, Santos EM, Leal MC. Aspects of women's satisfaction with childbirth care in a maternity hospital in Rio de Janeiro. Cadernos de Saúde Pública. 2004;20:S52-S62.
Publish in International Archives of Medicine

International Archives of Medicine is an open access journal publishing articles encompassing all aspects of medical science and clinical practice. IAM is considered a megajournal with independent sections on all areas of medicine. IAM is a really international journal with authors and board members from all around the world. The journal is widely indexed and classified Q2 in category Medicine. 